\title{
Contribution rates of some aspects of attention in the decisions of kata judges in karate sport \\ *Dr/ Hesham Hegazy abdelhameed
}

Introduction and problem of research:

Mental processes have received great interest from scientists and researchers because they are important in conception and understanding athletic performance of sports, which helps to improve the level of performance as well as learning processes, which in turn help the individual to reach the highest level possible in the type of sports activity practiced. (3: 6)

Medhat Mohammed Abu Al-Nasr (2009) saw attention as a functional process that guides the individual's feelings towards a new behavioral attitude،Or it is the process of focusing the feeling on a particular sensory process arises from the external stimuli in the behavioral field of the individual at any given time the individual can change his attention to any of the stimuli. (16: 70)

Mahjoub Ibrahim (2009) noted that attention in the sports field includes several aspects and that access to high levels of sports depends largely on the growth and improvement of these aspects, as each activity requires these aspects, but in varying percentage and degrees. Attention is one of the necessary conditions for a successful observation and is characterized by a state of mental alertness or vigilance so that the individual will be aware of facts, circumstances or other things. $(15: 47,49)$

Mohammed Al-Arabi Shamoun (2001) pointed out that the ability to focus varies among athletes, some of whom are more alert than others, and some are prone to disturbance and distraction due to poor ability to selection and attention divert . The intensity of concentration requires a tremendous amount of mental energy and therefore the feeling of tiredness and less alertness when concentration for a period of time, and it

Assistant Professor, Department of Curricula and Methods of Teaching Physical Education, Faculty of Physical Education, Mansoura University 
seems that the concentration of attention is faced with violent mental effort may cause the loss of concentration altogether. Concentrate is a skill that can be developed by training and repeating concentration on the stimuli required. The training must be done in periods appropriate to the duration of Competitions in various sports. (17: 265).

Abdulrahman

Mohammed Ahmed (2013) explained that the role played by the referees in both individual and team sports is a cornerstone of any competition, There is no complete sports competition without a referee that manages it and applies the international rules of the game and this is the exclusive jurisdiction of the arbitral tribunal. The distinguishing of the referee and the high level that would leave the positive impact for players, coaches, administrators and the fans, which gives each element of these, reassurance and thus raises the level of the game (1: 217)

Ahmad Al-Sayed AbdulSalam (2010) noted that karate sport is one of the sports activities which depends in evaluation of the performance technique and the beauty of motion such as gymnastics, diving, ballet and judo. and thus a problem arises when evaluating the competitions in a judges manner. As a result of dependence of referees on self evaluation, there is some doubt in its results and that is a part from objectivity, So such sports require a high level of selection and to have a high level of precision in the selection of judges. so Karate sport is one of those sports that requires precise specifications in the selection of judges, in both side physically and mentally, (4: 3).

it has become clear that the attention in karate is very important as it is characterized by the multiplicity of skills and the variety and speed of performance as well as the diversity of kata performed by the player, This requires the referee or judge to have very high degrees of attention to its different aspects, so that he can make the right decision in the least possible time, As the aspect of attention is important for athletes and karate players in general, it is more important to the referees and judges in the sport of Karate in particular, as they rely directly 
on many aspects of attention in the issuance of judgments and decisions on the performance of the player, Where as each players performance own Kata inturn on the carpet before the judges. after the second player end his performance, both players leave the field and wait for the decision of the judges who raise the blue or the red flag to announce the winner (Aka, Ao) in a few seconds after the performance of the Kata.

\section{Nakayama}

defined the kata as a series of interrelated defensive, offensive, strike, blockage and kicking techniques, arranged in a logical sequence $(26: 12)$.

Corrigan (1995) and Dan (1988) showed that kata is a Japanese word that has no synonym in English, the common used term in the world. It is defined as a series of movements of different types of defense and counterattack Against the attack of imaginary opponents " (23: 76) , (24:12).

Hesham Hegazy \& Mahmoud Abdel- Dayem (2017), believe that the kata is a "set of defensive and offensive skills, which consist of blocking, punching, striking, kicking and imbalance performed by the individual from different situations in a synchronous or consecutive way in different directions and speeds using hands and feet, In a logical sequence against imaginary competitors and an internationally agreed-upon coordination framework. It is a key pillar in the belt-up test (13: 167)

The Karate rule (2017) decided that the assessment of karate performance is based on the jury method. The jury consists of 5 referees or judges. The Kata chief judge sits on the outer edge of the playground facing the competitors. The other four judges sit in the corners of the competition area, allowing them the best vision. Each judge has two flags, one red and one blue, And that the competitors must perform different kata in each role and once the kata is performed, it is not permissible to return it. The judges must pay good attention while evaluating the performance of the players and it is based on three main criteria (compatibility, technique, performance). Each criterion includes a set of elements The judges focus their attention on them during the performance evaluation. (27)

In other words, the team of judges in the playing area waits until the player of the red corner (Aka) performs his kata and then goes out of the field. 
Then the blue corner (Ao) performance another kata and also goes outside the field and then with a signal from the chief judge, Each of them raise either a blue or red flag according to the winning player from their point of view, and here the researcher wonders whether all judges have the same amount of perception and the same attention that are likely to have a significant impact on the outcome of their decisions.?

Each player has his or her own kata, which is different from the rest of the other katas according to many variables such as (the school of the contestant - the type of skills played by the player, the number of kata movements performed by the player as each kata has a fixed number of movements (heian shodan 21 Movements), (Super embi 100 movements) The performance time of the kata, as each kata has its own performance time and its kinetic rhythm and the least time is 40 seconds (heian shodan) and the maximum is (150 sec super embi) Performance trends for each kata)(12:30).

The Karate rules (2017) states that karate referees and judges must focus their attention fully on the game, carefully monitor each contestant and judge each of the contestants correctly during the game and should not talk to anyone other than the referee the other judges and The contestants (27)

Laboratory researches have shown that the ability to retrieve past experiences in the form of mental images, varies from one individual, to other, which means that the mental images of a scene, for example, differs in their clarity, accuracy, and compatibility with the truth for two individuals who see the same scene under the circumstances (21:3)

Ahmed Ezzat Rajeh (1994) confirms that the subjective factors of perception, which are physical, psychological, social, experiential, and mood factors, make people differ in perceiving one scene, one melody or one person. Instead of saying that cognition is a response to a position, we should say that it is the result of the individual's interaction with the situation - the interaction of subjective factors with objective factors (5: 219, 220).

The problem of the research clarifies That kata judges in karate must keep a very large amount of information and details of the motor performance of both 
players so that they can make the right decision according to the above variables and in the presence of many distractions; audio or visual, during tournaments and competitions such as (shouts and alerts of coaches, Viewers' cheers, cameras, The pressure placed on them by the chairmen of the jury who monitor their decisions and performance), which may affect the mental state of the judge, and therefore his attention such as (attention concentration, attention intensity, attention divert) may affect on the decision he makes. This often results in an incorrect decision that may cause a player, a team or a state to lose a competition. and the loss of months or years of time and effort in the preparation and training, as well as the result this decisions impact on the player and the coach and the media and the fans. Therefore, the researcher sees the need to identify the contribution of some aspects of attention in the decisions of kata judges in karate.

\section{Research aim :}

- Recognition of the contribution of some aspects of attention in the decisions of Kata judges in karate sport.

\section{Research hypothesis:}

The rate of the contribution of some aspects of attention in the decisions of kata judges in karate sport varies.

review studies :

The researcher

conducted a comprehensive reference survey of the research and studies related to the subject of this research, such as the study of: Hatem Mohammed Mohamed (2014) entitled: Analytical study of the mental abilities affecting decisionmaking in the referee of football, (7). Abdul Rahman Mohammed Ahmed (2013), entitled: The relationship of concern to focus attention on the referees of football in Sudan,(11). Mahjoub Ibraheem Yasin (2009) entitled: The relationship between the aspects of attention and the skill of accuracy shooting football, (13). Hind Suleiman Ali Hassan (2007) entitled: Standardization of the skills of attention scale For referee scoring points in bowling sport, (22). Abdulrahman bin Mousaed al-Zahrani (2003) entitled: The impact of the state of anxiety and confidence on the focus of attention and reaction speed of the volleyball referees Saudi, (10). Ahmed Mahmoud Ibrahim (1992) entitled: The relationship between the level of functional efficiency of the central nervous system and some 
characteristics of attention as a determinant of the selection of karate players, (6). Ali Hassanein Mohammed Habasullah, Habib Al-Adawi (1989) entitled: The ability to focus attention on volleyball referees, (12). Rachida Mohammed Hussein AlAzabi (1984) entitled: Defining the attention of the referees of some of the team games. In the Arab Republic of Egypt, (9).

None of these studies have shown the relationship between the aspects of attention and the referees and judges of karate, and this indicates the importance of the present study as an attempt to identify the percentage of the contribution of some aspects of attention in the decisions of Kata judges in karate sport.

\section{Research procedures:}

Research method:

The researcher used the descriptive approach to suit the nature of the research.

\section{Research sample:}

The research sample has been chosen randomly among referees of Dakahlia karate region. The primary sample of the study was 10 referees (second and third grade) $83 \%$ Percentage with a mean age of 25.40 years, a standard deviation 1,074 and a skewness of 0.322 , indicating homogeneity of all the sample.

\section{Executive Steps to Search:}

\section{1- search tools :}

- The researcher used the reference survey to identify different aspects of attention to be presented to a group of academic experts in the field of karate sport and sports psychology, So as to identify the most important aspects of attention that affect the decisions of judges in karate(3), (5), (7), (8), (15), (18), (20)

- Expert opinion to determine the most important aspects of the attention of kata judges in the sport of karate, and the researcher has identified the most important aspects of the following attention (1 attention concentration, 2 attention intensity, 3 - attention stability, 4 - attention divert) Attachment (1),(2),(3).

- The technical tests: Based on the researcher to assess the level of performance by the sincerity of the arbitrators, where the researcher used 10 referees (Second and third degrees) registered with the Egyptian Karate Federation to assess the skill level of the sample in the study, In the same manner as the competitions of the Egyptian 
Karate Federation. Attachment (4).

\section{The first exploratory study:}

The Borden Infemov test, as well as the Grid Concentration test, were used to focus attention on measuring the attention aspects of the study. Dorothy Harris The Arabization of Mohamed El Arabi Chamoun. Attachment (5) on A random sample of karate players (black belt) belonging to the Dakahlia Karate area (10) players under the age of 21 who meet the conditions of admission as new referees, as well as (10) players second grade (belt blue and brown) the same age stage belonging to Dakahlia For karate, so as to calculate the scientific coefficients of the test of validity and stability.

\section{A- validity:}

The method of validity of differentiation was used to calculate validity by comparing the scores of the special group and the scores of the nonspecial group of the survey members of (20) players as shown in Table (1)

Table (1)

\begin{tabular}{|c|c|c|c|c|c|c|}
\hline \multirow[t]{2}{*}{ m } & \multirow[t]{2}{*}{ variables } & \multicolumn{2}{|c|}{ special group } & \multicolumn{2}{|c|}{$\begin{array}{c}\text { non- special } \\
\text { group }\end{array}$} & \multirow{2}{*}{$\begin{array}{c}\mathbf{T} \\
\text { value }\end{array}$} \\
\hline & & mean & Std & mean & Std & \\
\hline 1. & $\begin{array}{l}\text { Grid Concentration test } \\
\text { (Attention Concentration) }\end{array}$ & 8.00 & 1.05 & 4.70 & 1.16 & $6.66^{*}$ \\
\hline 2. & Attention intensity & 109.90 & 11.59 & 92.42 & 2.87 & $4.74 *$ \\
\hline 3. & Attention stability & 0.92 & 0.04 & 0.75 & 0.03 & $10.29 *$ \\
\hline 4. & Attention divert & 21.43 & 1.08 & 18.69 & 0.63 & $7.78^{*}$ \\
\hline
\end{tabular}

table $\mathrm{T}$ value is at a significant level of $0.05=1.833$ significant * It is clear from Table (1) that there are statistically significant differences at $(0.05)$ between the scores of the special group and the nonspecial group of the sample of the exploratory study in the Borden Infemov test and the Grid Concentration test for the special group where all computed values were larger than the table values Indicating the validity of the measure. B - Stability: 
To find the coefficient of stability, the researcher used the application of the test and re-application after a period of time (15) days on (10) the first degree player who meet the conditions of admission as new referees, belonging to Dakahlia
Karate on Tuesday 31/5/2016, and re-application on the same sample on Tuesday 14/6/2016 to find the correlation coefficient between the results of the first and second measurements, as shown in Table (2).

Table (2)

Stability coefficients of the Borden Infemov test and the Grid

Concentration test for concentration of attention $n 1=n 2=10$

\begin{tabular}{c|l|c|c|c|c|c}
\hline \hline \multirow{2}{*}{$\mathbf{m}$} & \multirow{2}{*}{ variables } & \multicolumn{2}{|c|}{$\begin{array}{c}\text { first } \\
\text { application }\end{array}$} & \multicolumn{2}{c|}{$\begin{array}{c}\text { second } \\
\text { application }\end{array}$} & \multirow{2}{*}{$\begin{array}{c}\mathbf{r} \\
\text { value }\end{array}$} \\
\cline { 3 - 6 } & mean & Std & mean & Std & \\
\hline \hline 1. & $\begin{array}{l}\text { Grid Concentration test } \\
\text { (Attention Concentration) }\end{array}$ & 8.00 & 1.05 & 7.80 & 0.92 & $0.918^{*}$ \\
\hline 2. & Attention intensity & 109.90 & 11.59 & 105.13 & 11.28 & $0.939^{*}$ \\
\hline 3. & Attention stability & 0.92 & 0.04 & 0.91 & 0.03 & $0.925^{*}$ \\
\hline 4. & Attention divert & 21.43 & 1.08 & 21.10 & 0.99 & $0.879^{*}$ \\
\hline \hline
\end{tabular}

table $r$ value is at a significant level of $0.05=0.632$ significant $*$

Table (2) shows a statistically significant positive relationship at a significant level (0.05)Between the first application and the second application in the Borden Infemov test and the Grid Concentration test, indicating the stability of those tests.

Basic study:

The basic study was Applied from Monday 20/6/2016 to Tuesday $12 / 7 / 2016$ on the judges of Dakahlia Karate district where the Borden Infemov test and
Grid Concentration test were applied The tests were defined and the objectives of their application Its instructions and the objective of each test are the same conditions and procedures for each test attachment (4), and then used (5) laptops, (2) Hall to wait for the judges to evaluate (10) kata matches recorded on a hard disk (cd) Which has been done before in one of the official Competitions and has been evaluated in advance (Men's Republic Championship 2015 
season), and the results of the evaluation of each judge was results Presenting :

Table (3)

The correlation coefficients between some aspects of attention in the research and decisions of kata judges in karate

\begin{tabular}{l|l|c|c|c}
\hline \hline $\mathbf{m}$ & \multicolumn{1}{|c|}{$\begin{array}{c}\text { aspects of } \\
\text { attention }\end{array}$} & correlation & sig & \\
\hline \hline & Attention intensity & 0.932 & 0.000 & significant \\
\hline & $\begin{array}{l}\text { Grid Concentration } \\
\text { test (Attention } \\
\text { Concentration) }\end{array}$ & 0.657 & 0.037 & significant \\
\hline & Attention stability & -0.088 & 0.405 & Non-significant \\
\hline & Attention divert & 0.010 & 0.490 & Non-significant \\
\hline \hline
\end{tabular}

It is clear from Table (3) that there is a significant correlation between attention intensity and concentration of attention and the decisions of the kata judges at a significant level (0.05) and a non-significant direct

\section{Table (4)}

Regression coefficients for some aspects of attention contribute to the results of decisions of Kata judges in Karate

\begin{tabular}{l|c|c|c|c|c|c|c|c}
\hline \multicolumn{1}{c|}{ variables } & $(\mathbf{B})$ & $\begin{array}{c}\text { (Std. } \\
\text { Error) }\end{array}$ & (Beta) & $(\mathbf{t})$ & (Sig. ) & (f) & (Sig. ) & (R2) \\
\hline \hline (Constant) & -13.105 & 4.170 & & -3.143 & 0.026 & & & 0.954 \\
\hline Attention intensity & 0.075 & 0.008 & 0.960 & 9.724 & 0.000 & 25.652 & $.002^{b}$ & \\
\hline $\begin{array}{l}\text { Grid Concentration test } \\
\text { (Attention Concentration) }\end{array}$ & 0.320 & 0.109 & 0.364 & 2.934 & 0.032 & & & \\
\hline Attention stability & 8.448 & 3.424 & 0.322 & 2.468 & 0.057 & & & \\
\hline Attention divert & 0.073 & 0.042 & 0.180 & 1.746 & 0.141 & & & \\
\hline \hline
\end{tabular}

Table (4) shows that there is a statistically significant effect For some aspects of attention in the results of the decisions of the kata judges where the value of recorded in the form prepared

for this attachment (4). relationship between the divert attention and decisions of kata judges. While there is an inverse relationship between attention stability and the decisions of kata judges. 
results of the decisions of the kata judges where the value of a function statistically significant level (0.05) While there is no statistically significant effect on the appearance (attention stability and attention divert) On the results of the decisions of the Kata judges.

As shown in the table, the percentage of the contribution of attention intensity in the results of the decisions of the kata judges is $96 \%$ while the percentage of contribution of attention concentration is $36.4 \%$. Since the regression line equation is:

$\mathrm{E}=\mathrm{C}+\mathrm{R} 1 \mathrm{I} 1+\mathrm{R} 2 \mathrm{I} 2$

Where: "E" estimated value of the dependent variable.

"C" constant value.

"R" regression coefficient.

"I" independent variable.

Thus the predictive equation is: $\mathrm{E}=\mathrm{C}+\mathrm{R} 1 \mathrm{x}$ attention intensity $+\mathrm{R} 2 \mathrm{x}$ attention concentration .

Evaluate degree $=(-13.105)+$ $(0.075) \times($ attention intensity $)+$ $(0.320) \times \quad$ (Attention

Concentration)

discussing of results:

In Table (3) it is clear that there is a statistically significant correlation between the appearance of Attention intensity and Attention Concentration and the decisions of the Kata judges, The correlation coefficient was $0.93,0.657$ at a significant level (0.05), While there is a positive relationship that is not statistically significant of the appearance of Attention divert The correlation coefficient was (0.010) at a significant level (0.05), While there was an inverse negative correlation between attention stability and the decisions of the kata judges where the coefficient of correlation was -0.088 .

As shown in table (4), there is an effect of some aspects of attention in the results of the decisions of the kata judges where the value $F$ is (25.652) is statistically significant at a significant level (0.05), There is a statistically significant effect on the appearance (attention intensity and Attention Concentration) On the results of the decisions of the kata judges where the value $\mathrm{T}$ is (9.724), (2.934), which are statistically significant at a significant level (0.05). While there is no statistically significant effect 
on the appearance(Attention stability and Attention divert) On the results of the decisions of the Kata judges where the value $\mathrm{T}$ is (2.468), (1.746) which are not statistically significant at a significant level (0.05).

As shown in the table, the proportion of the contribution of attention intensity in the results of the decisions of the kata judges is $96 \%$ while the percentage of contribution of attention concentration is $36.4 \%$.

The researcher attributed the existence of a statistically significant correlation between the appearance of the attention intensity and attention concentration and the decisions of the kata judges for two main reasons The first is the nature of the performance of the kata competition as it is a "set of defensive and offensive skills, which consist of blocking, punching, striking, kicking and imbalance performed by the individual from different situations in a synchronous or consecutive way in different directions and speeds using hands and feet, In a logical sequence against imaginary competitors and an internationally agreed-upon coordination framework. It is a key pillar in the belt-up test (13: 167), That is, the performance of the kata players is completely different from the Kumite performance The performance of kata is constant and the form of skill performance not varies from player to other You can not increase skill or delete skill, And the average performance time of most of kata that is performed does not exceed the two minutes in contrast to the Kumite, which takes at least 3 minutes per match, On the other side, the judges' staff is committed to specific performance appraisal criteria, so that mental processes, attention intensity and concentration of attention are greater than the appearance of attention retention or diverting attention, . The second reason is that beginners referees (second and third grade) are not experienced and have most of their interest and mental processes Oriented and focused attention as they have not yet had sufficient experience to have the stability attention and diverting attention. Ahmed Khater and Ali al-Baik 
(1996) (7) emphasize that attention processes occur at different degrees of strength. When an individual performs motor skills during sports activities, there is a difference in the intensity of the attention from moment to moment When fatigue happens when attention is less and may be completely absent in the case of stress, which leads to inactivity in the accuracy of processes on the cerebral cortex (7: 531). This is what the International Karate Law (2017) stated, The judges must pay good attention while evaluating the performance of the players and it is based on three main criteria (compatibility, technique, performance). Each standard includes a set of elements that the judges focus on during performance assessment, and karate referees and judges must focus their attention fully on the match, carefully monitor each contestant and judge each of the contestants correctly during the match and should not talk to any Someone other than the principal referee, other judges and contestants. (27). This is in line with the findings of Hassanein Muhammad
Habasullah, Habib Al-Adawi (1989). As the age and experience of rulers increases, mistakes are reduced and the ability to focus attention increases,(9) As Mohammed Allawi (2012) (19) points out that the process of focusing attention means narrowing or stabilizing it towards a particular emotion and continuing to draw attention to this chosen stimulus for a period of time (19: 307). This is well suited to the performance of Kata as a set of fixed and specific skills that perform in a short time. Mohammed Al- Arabi Shamoun (2001) (17) points out that the ability to focus varies among athletes, some of whom are more alert than others, and some are prone to disturbance and distraction due to poor ability to pick and divert attention. (17: 265). The results of this study are consistent with those of Hatem Magdy (2014)(11), Johannes Hack, Andre Robb and Daniel Mimert (2009) (25) The results showed a statistically significant correlation at a significant level (0.05) As a mental ability and decision-making for football 
and basketball referees. As well as the results of the study of Hassan Saleh (2005) (10) where the results showed the existence of a relationship of positive correlation statistically between the aspects of attention (attention concentration, attention intensity) and the accuracy of the referees decisions ,He also found that there was no statistically significant relationship between the attention stability and the Attention divert and the accuracy of referees decisions As well as the results of the study Rachida Mohammed (1984) (22) which confirmed that whenever rise the degree of handball referees, rise their levels of attention stability and the Attention divert.

From the above Verifies search hypothesis Which states that " The rate of the contribution of some aspects of attention in the decisions of kata judges in karate sport varies".

\section{Conclusions:}

1- There is a statistically significant correlation between the appearance of the attention intensity (0.923), attention concentration (0.657) and decisions of kata judges in karate sport.

2 - It was possible to reach the aspects contributing to the decisions of kata judges in karate sport, which attention intensity by $96 \%$, attention concentration is $36.4 \%$.

3 - The predictive equation is derived from:

$\mathrm{E}=\mathrm{C}+\mathrm{R} 1 \mathrm{x}$ attention intensity $+\mathrm{R} 2 \mathrm{x}$ attention concentration. Evaluate degree $=(-13.105)+$ $(0.075) \times($ attention intensity $)+$ $(0.320) \quad \times$ (Attention

Concentration).

\section{Recommendations:}

1- Giving attention to the development of the aspects of attention contributing to the decisions of kata judges in karate sport, Through some visual mental exercises for judges.

2- subjecting the new referees to test the aspects of attention when promotion to the higher grades.

3- Use the predictive equation of the study in the selection of kata judges in karate sport.

4. Performing similar studies using different samples on kumite in karate sport.

Arabic reference:

1- Abdul Rahman Mohammed

Ahmed: The Relationship of 
Concern to attention concentrate on the Football referees in Sudan, Journal of Human Sciences, Volume 14, Issue 3, Sudan University of Science and Technology, 2013

\section{2- Abdulrahman bin}

Mousaed Al-Zahrani: The Influence of the State of Concern and Confidence on the Attention Concentration and Responsiveness of Saudi Volleyball referees, Unpublished Master Thesis, College of Education, King Saud University, 2003.

3- Ahmed Amin Fawzy: Sporty psychology - principles and applications, technical printing and publishing, Alexandria, 1992

4- Ahmed El Sayed Abdel Salam Amer: Designing a Psychological Skills Scale for Karate referees, Master Thesis, Faculty of Physical Education for Boys, Banha University, 2010

5- Ahmed Ezzat Rajeh: Origins of Psychology, Dar Al Ma'arif, Cairo, 1994

\section{6- Ahmed Mahmoud}

Ibrahim: The relationship between the level of functional efficiency of the central nervous system and some characteristics of attention as a selector for the selection of karate players, the scientific journal Faculty of Physical Education for girls Fleming, Alexandria University, 1992

7- Ahmed Mohamed Khater, Ali Fahmy Al-Beek: Measurement in the Sports Field, Modern Book House, 4, 1996

\section{8- Ahmed Zaki Saleh:}

Educational Psychology, edition 14, the Egyptian Renaissance Library, Cairo, 1992

\section{9- Ali Hassanein Mohammed} Habasullah, Habib AlAdawi: The Ability to Focus Attention on Volleyball referees, The Scientific Journal of Physical Education and Sport, Issue. 4,Helwan, 1989

10- Hassan Saleh Mahdi: The aspects of attention and its relation to the accuracy of the decisions of basketball referees, Master, Faculty of Physical Education, University of Babylon, 2005

\section{1- Hatem Mohamed Magdy} Mohamed: Analytical study of the mental abilities affecting decision-making in the referee of football, Master Thesis, Faculty of Physical Education Mansoura, Mansoura University, 2014 
12- Hesham hegazy abd elhameed: Estimate the level of motor memory using Suggested E-measurement and its relationship with the decisions of kata judges in karate, Research published in the international scientific magazine "Theories \& application - the international edition" - TAIE Faculty of Physical Education for Boys Alexandria University February 2012

13- Hesham hegazy abd elhameed, Mahmoud Ahmed Abdel Dayem: Basic principles in karate sport, $\mathrm{Al}$ Manar Library, Mansoura, 2017.

\section{4- Hind Sulaiman Ali} Hassan: Standardization of Attention Skills Scale for the referee of score points in Bowling Sports, Assiut Journal of Physical Education Sciences and Arts, Issue 25, part 2, 2007

\section{5- Mahjoub Ibrahim}

Yassin: The relationship between the aspects of attention and the skill of accuracy correction football, Journal of Sports Science, the first issue, University of Diyala, 2009

16- Medhat Mohamed Abu El-Nasr: The Power of
Concentration and Memory Improvement, Arab Group for Training and Publishing, Cairo, 2009

\section{7- Mohamed El-Arabi} Chamoun: Mental Training in the Mathematical Field, edition 2, Dar Al-Fikr Al-Arabi, Cairo, 2001

\section{8- Mohamed El-Arabi} Chamoun: Soprts Psychology and Psychological Measurement, The Book Center for Publishing, edition 1, Cairo, 1999

19- Mohamed Hassan Allawi: The psychology of sport and physical practice, almadany Press, Cairo, 2012

20- Mohsen Mohammed Ahmed: A series of cognitive psychology (5) Educational Psychology, Al-Mutanabbi Library, Dammam, without a date

\section{1- Nubi Mohammed}

Hassan: The timeframe for the survival of the information in the memory of students of architecture (applied study on students of the decision theories of architecture at King Saud University), research published in: Journal of Engineering Research, Faculty of Engineering, University of Menoufia, Egypt, Volume 30, 
Issue 0.2, April 2007, p2,3,7, Available at http://faculty.ksu.edu.sa/vir . . / Documents/Papers/r.\%. ฯ The r.\%Timer.\%Periodr.\%ofr.\% Retaining r.\%Information r.\%i n r.\%Architectural r.\%Students $\%$ r.\%११\%^.\%rmemory.pdf

22- Rachida Mohammed Hussein Al-Ezabi:

Determination of the aspects attention for referees of some of the team games. In the Arab Republic of Egypt, unpublished master thesis, Faculty of Physical Education. For Girls, Alexandria University, 1984

Foreign references:

1- Corrigan. Ralph:. Karate (Made Easy), published by sterling publishing company, Inc, New York, 1995.

2- Dan , Bradley : Step by Step Karate skills , Hamlyn company , Hong Kong , 1988.

3- Johannes Hack, Andre Rupp \& Daniel Memmert : Attentional Mechanisms in Sports Via Brain-Electrical Event- Related Potentials, Research Quarterly for Exercise and Sport, 80:4 , 727738 , DOI: 10. 1080/02701367.2009.10599614

4- Nakayama, M: Best Karate (Heian.Tekki), Kodansha, International, LTD, New York, 1981.

\section{Internet References}

1- https://www.wkf.net/pdf/ wkf-competition-rulesversion9-2015-en.pdf Wednesday 15/2/2017 